\title{
The Complexity of Care
}

\author{
STEVE COLLINS AND HERMIA TING \\ University of British Columbia, (Canada)
}

\begin{abstract}
The profession of teaching is unique because of the extent to which a teacher becomes involved in the lives of their "clients". The level of care required to support students well can be intense, confusing, and overwhelming. Relationships co-evolve within an ever-changing process and care is considered an essential aspect of complex relationships between students and teachers. While we do have many standard guidelines to help us, such as codes of ethics, rules, and policies, this paper examines their limitations. The ethics of care require more than standards or guidelines. To mitigate these limitations, we offer a more complex way of thinking as a way to navigate the dynamic disequilibrium of caring relationships. In the process, we emphasize the need for caring teachers to embrace their own vulnerability. This way of thinking provides us with an ecological ethical approach for engaging in professional relationships that promotes respect, safety, and selfworth for all involved.
\end{abstract}

\section{Introduction}

Teaching can be described simply, in a general sense, and it often is by administrators, unions, and in job postings. In practice, however, a teacher is a jack-ofall-trades: counsellor, confidante, first aid attendant, a connoisseur of many subjects, and may take on a parent-like role in many cases. Although it may not be in the description in the afore-mentioned job posting, we expect ourselves to do all these things, because we have in our care a special group of clients - students. They are vulnerable young beings who have not yet fully developed socially, emotionally, intellectually, or physically. That is what makes education a truly unique profession. Teachers are immersed all day in the lives of their students, continually getting to know them, keeping up with changes in their lives at school and at home. Clearly, teachers greatly affect students' lives. Likewise, the care of students permeates the lives of their teachers. 
Teaching is more than a full-time job in the sense that our students occupy our thoughts and actions after we leave the school at the end of the day. Most teachers work beyond the school's timetable, thinking about, planning for, and empathizing with their students. Teachers care.

This paper is a conceptual exploration of the nature of care in teaching. It is based on the writings of prominent authors in the fields of human relations, ethics, and complexity. We also draw on our own experiences as teachers and university educators, and the many discussions that we have had with our colleagues on the topic of caring teachers. Although we view this paper as conceptual, there is a complex interplay between our lived experience and our conceptual research. The former motivated our inquiry into the latter, while our practice is enhanced by the emergent concepts. We believe this adds authenticity to our report here and, hopefully, some practicality to those who would make application to their daily practice.

We assert that teaching and caring are not separate. Teaching is caring. We can not properly teach without caring, but that invites uncertainty, confusion, and self-doubt. There is no script to guide caring teachers and we will regard such attempts with suspicion. This paper will address the complexity of care in teaching and we hope to provide - not solutions - but a new clarity of thinking while immersed in the disequilibrium that accompanies the nurturing of our students.

The strategy for this paper is to summarize a perspective on how teachers care based on a variety of writings. We will identify the limitations of standards and codes of ethics based on a complex way of thinking and use this view in mitigating challenging practices. We will project potential issues of stress and vulnerability for teachers caring holistically and spontaneously. We will draw on the work of social psychologists involved in this topic and temper it with a complex way of thinking that is supported by current researchers and inspired by writers from the past.

\section{The Literature of Care}

When the topic of care in education arises, the name Nel Noddings might be immediately associated, since her work dominates much of the thinking in this area. We believe that her influence has had a profound influence on how teachers might care for their students. We also believe that her writing often approaches a recognition of the complexity of caring in actual practice. Care is not merely complicated. It emerges from unpredictable interconnected relations.

Lynn Owens and Catherine Ennis wrote The Ethic of Care in Teaching: An Overview of Supportive Literature in 2005. It is a comprehensive review of the contributions of many researchers and writers, including Noddings, in support of care in education. While citing overwhelming support of Noddings efforts, Owens and Ennis also address some shortcomings and a critical limitation that this paper will examine in depth with the aid of a complex view. 
While many teachers say they care about students ... without a true understanding of what this really means, teachers may become overwhelmed by the realities of care. (Owens \& Ennis, 2005, p. 392)

The italics are ours and are meant to emphasize firstly that a universal truth of understanding the nature of care in specific cases may be unattainable. Secondly, if the complexity of caring for students is left unexamined, it can be overwhelming and extremely stressful, sometimes to the point of debilitation. We will point to instances where Noddings would appear to sympathize with these cautions but never really addresses them in full. We will first situate Noddings in the related literature and then use her grounding to extend understanding through a complex perspective.

Owens and Ennis cite an extensive body of research in the 1990's by many researchers. They report a diversity of terminology across disciplines in researchers' attempts to categorize care. Tarlow (1996), for example, developed eight characteristics describing the phases of the caring process. Mercado (1993), used collaborative action research to describe four themes that are typical of caring. These authors offer a general, wide ranging support of Noddings' theoretical framework of the ethic of care, but, like ourselves, they seek to extend this thinking and to narrow the focus to enable understandings of care in more specific instances. However, as described above, these authors tend to reduce the complexity of care in real practice by constructing categories, characteristics, and themes. The overlapping diversity of these constructions show that no one model can provide a complete and definitive answer to how to care in every case.

We intend to highlight the limitations of categorical thinking around such a human and dynamic concept, especially when it comes to the application of categorical thinking in formulating codes of conduct and ethical standards. Rather we will take a complex approach and embrace the whole of the concept of care in practice with all of its interconnections, diverse manifestations, and the attendant disequilibrium that will arise from such a view.

Nel Noddings offers a definition of care that provides a starting point for this paper: relational care, that is, in its simplest form, "a connection between two human beings" (2005, p.15). From here we will begin to examine the complexities that might arise from the practice of care.

The desire to be cared for is almost certainly a universal human characteristic.... In schools, all kids want to be cared for in this sense. They do not want to be treated "like numbers," by recipe - no matter how sweet the recipe may be for some consumers. When we understand that everyone wants to be cared for and that there is no recipe for caring, we see how important engrossment (or attention) is... Caring is a way of being in relation, not a set of specific behaviours. (Noddings, 2005, p. 17)

Noddings' characterization of care highlights the issue of connection. It is this very concept of human connection - relational care - that sets outstanding teachers apart from their colleagues. Many authors have examined the issue of what characteristics are most valued in teachers. They have found that valued teachers are those who have discovered 
a way to demonstrate care (Murphy, Delli, \& Edwards, 2004; Polk, 2006; Farr-Darling, Erickson, \& Clarke, 2007).

The idea of interconnection among people suggests complexity. Complexity, in this sense, is much more than something that is merely highly complicated. As we shall see, it is interactive, dynamic, emergent, and usually unpredictable. With relationships, there is no formula that could be predictive or encompassing. While it would be convenient to develop a recipe for care and to define the exact boundaries and limits, our understanding of complexity tells us that it seems extremely challenging to do so satisfactorily for all involved.

\section{The Limitations of Modern Science}

We live in a "reductionist" society. The modernist view tends to categorize, label, delineate, and standardize many aspects of our lives. In school, we differentiate among grades, marks, classrooms, abilities, disability types, behaviors, and gender. We do this because the world is so complex that we cannot understand it as is. There is a need to reduce the complexity by constructing sub-themes that are smaller and easier to understand. For the most part, this works well and we have made amazing advances because of our ability to frame certain elements of the complexity we live with and set those elements apart so we can examine them outside of all the chaotic interconnections.

I do not wish to suggest that the dichotomies that we construct and through which we make sense of the world are unhelpful, but that they should not be regarded as absolute. ... I invoke the pragmatist measure of truth and argue that such constructions are valid insofar as they are useful. (Davis, 1996, p. 2)

Indeed reductionism is unavoidable. The scientific method generally assumes a reductionist approach. In the last three centuries our society has made astounding gains in medicine, transportation, communications, weaponry, individual comforts, and freedoms. Some of the issues we have not succeeded so well with are the disparity between rich and poor, massive starving populations, western apathy, terrorism, pollution, and weaponry that may destroy us all. We suggest that these are based on false dichotomies - the us/them vision, the black and white - all those manufactured binary concepts that are not rooted in a natural, interconnected vision of the world as a whole.

We can ask ourselves, "Are we objective scientists, analyzing our students, our class, and our school, to match against standard student achievement and standardized teaching practice" or "Are we human beings interacting in an authentic way to engage in fluid, changeable relationships with students"?

Notice the binary trap invoked by these questions. These two choices are not separate. We can intertwine both perspectives to help us in our efforts to be good teachers. As Davis (1996) pointed out earlier, it does not really have to be one or the other and many different views can be useful. The distinction we want to make is that with a complex way of thinking, the natural tendency to be immersed in social situations 
can be valued highly, regardless of our tendency to break down social events or practices into isolated pieces.

\section{Care and Complexity}

We tend to forget it is we that make the arbitrary distinctions. People make categories. Nature does not. Nature can be conceived of as complex. So while reductionism helps us, it cannot tell the whole story. The confusion between our constructed reductionist view (regardless of how complicated it is) and natural complexity can lead to unfortunate misunderstandings about how interconnected elements influence each other within a complex whole. This lack of a critical distinction may lead to inflexibility when concerning ourselves with fluid, dynamic systems like classrooms and students. Our society attends a great deal to labels and categories. Labels often come from the medical or scientific community and can be tied to economic factors (in that they can determine funding priorities). Because of this, these labels can carry such authority that we may well lose our sense of who each individual really is and what he or she is actually capable of outside of the specific designation that is used to identify the student.

In a time when teachers feel almost unbearable pressure to standardize what we do, it is important to begin with the conviction that we are no longer teaching if what we teach is more important than who we teach or how we teach. (Tomlinson, 2003, p. 10)

Based on Tomlinson's assertion, we wish to suggest again that a distinction that sets apart excellent teachers is care. Excellent teachers get to know individuals beyond labels and recognize all that lies outside particular categories as also being essential, connected (rather than discrete) aspects of students. We never know everything about individuals since they are complex, with invisible internal interactions as well as unpredictable external interactions with others.

... a learner is a complex unity that is capable of adapting itself to the sorts of new and diverse circumstances that an active agent is likely to encounter in a dynamic world.

(Davis and Sumara, 2006, p.14)

With this realization, teachers (as learners themselves) are constantly exploring both the potential and the evolving nature of individual students. This can lead to surprises that can inspire renewed and effective ways of interacting with individuals. Discovering new interests, for example, can provide a vehicle for engaging learning opportunities. Discovering fears or dislikes, can guide us in removing obstacles. A teacher demonstrating care gains insight into those complex interactions. Demonstrating care means that the teacher can maintain an openness about students' feelings, opinions, and actions - and reserve judgment.

In discussing the ethics of care, Noddings prefers words that suggest the development of strong relations such as "...responses and responsibility, preservative love, attention, attentive love, nurturance, needs, caretaking/care-giving, receptivity, reciprocity..." (p. 146). Clearly this language suggests going beyond the simple projection of ethical codes of conduct. Noddings' distinction in language is helpful but in extending 
her logic to actual practice, we will require more help in unique situations when responding in the moment.

Spontaneous responses in unexpected situations could be overwhelming if teachers look for a formula to help them achieve excellence, given the premise that complex systems are impossible to fully predict or control. They will want to know how to care, how much to care, and how much caring is too much for either the teacher or the student. They will want to know the qualities and limits of care in a teacher-student relationship. The answer to this question will be different for every student and every teacher. Care looks different depending personality, style, length of relationship, past experiences, and an infinite number of other considerations.

A complex way of thinking can provide us with a way to conceive of care as an ever-evolving process that is constantly adapting in each unique situation. At the same time, we can consider the arbitrarily constructed elements that are reduced from the whole, while keeping in mind that they are all connected, influencing each other in a dynamic way. This way of thinking provides us with a lens for making sense of interconnections and informs us in a general way of possible responses to changing and unexpected social situations.

\section{Standards, Guidelines and Ethics}

Perhaps expectedly, aspects of complexity have been described by a multifaceted, overlapping, interacting, dynamic listing of concepts attributed to a complex way of thinking (Weaver, 1948; Capra, 1994; Davis \& Sumara, 2004; Clarke \& Collins, 2007). Here we identify, define, and apply the most suitable of these concepts in our exploration of the idea of care in teaching. These are presented as interwoven perspectives rather than categories. Key words are highlighted in italics.

All complex systems are in a constant state of disequilibrium. This does not mean they are unstable but that they are in a continual process of evolution. They are not in static balance (Prigogine. 1977). Productive caring relationships and their attendant interactions are always in stable disequilibrium.

We must be careful now to not conflate this conception of disequilibrium with that of Jean Piaget. He described developing knowledge as "a process leading from certain stages of equilibrium to others, qualitatively different, and passing through multiple 'non-balances' and re-equilibrations $(1977,3)$. Re-equilibrations refer to resolutions of disequilibrium, through learning, by becoming newly adjusted states of equilibrium. No doubt this is part of the learning process that we refer to below. However, when we look at the ongoing nature of relations beyond specific discomforts and resolutions, in general, they are in a constant state of change. Stability, rather than resolution, is the continuing challenge for relationships. For this reason we will draw on the work of social psychologists and researchers later in this discussion.

When we care, this lack of permanent resolution and the focus on a never-ending process of growth can be quite disconcerting. However, disequilibrium is an inherent part of creativity and learning (Collins, 2004, p. 9). It cannot be avoided in relationships 
and, rather, might even be embraced. When we feel the discomfort of disequilibrium, we are likely learning. "...a learning system is any complex form that can adapt itself to changing circumstances" (Davis \& Sumara, 2001, p. 88). Change is not always positive. In the case of caring relationships, change means we are learning more about each other and gives us clues as how to be together productively but there are no guarantees of success.

All this complexity keeps people on the edge of chaos. It is important to be on that edge because that is where creativity resides, but anarchy resides there too. Therefore, effective leaders tolerate enough ambiguity to keep the creative juices flowing, but along the way, ... they seek coherence. Coherence making is a perennial pursuit. Leadership is difficult in a culture of change because disequilibrium is common (and valuable, provided that patterns of coherence can be fostered). (Fullan, 2001, p. 6)

Relationships become cohesive because of the shared values, ambitions, and interests of the participants. Commonalities serve to draw people together. In terms of a complex view, these are redundancies to make note of since they motivate further interaction and development. However, relationships also grow because of diversity. Diversity of viewpoints, styles, and experiences, push the relationship beyond the comfort of redundant shared values. Forcing participants to consider and interact with new perspectives creates disequilibrium, and therefore creates learning about the relationship.

Such variation is the source of novel responses. When a complex system is faced with a problem, an adequate solution might be found in these pools of diversity. Such diversity is always and already present in a classroom collective. However, it is useful only to the extent that it can be appreciated by other agents in the system - which points to a second key condition, redundancy. For a complex unity to be sustainable, its agents must have enough in common ground to maintain interactions and to compensate for one another's lapses. (Davis \& Sumara, 2006, p. 316)

Both redundancy and diversity are needed in a growing relationship. They are in every stable complex system.

We contend that to do the greatest good we must respond uniquely and to situations through our individual relationships and this response cannot be fully predicted before the situation occurs. This goes beyond the way that standardized rules are capable of functioning. Certainly standard criteria could fulfill the requirement for shared values, even if they are imposed in a top-down manner. However, we will still require the ability to be divergent in our responses to novel situations if a caring relationship can adapt and survive.

As an exemplar of standards and codes, let us refer to the first of eight Standards for the Education, Competence \& Professional Conduct of Educators in British Columbia (2012):

Educators value and care for all students and act in their best interests.

Educators are responsible for fostering the emotional, esthetic, intellectual, physical, social and vocational development of students. They are responsible for the emotional 
and physical safety of students. Educators treat students with respect and dignity. Educators respect the diversity in their classrooms, schools and communities. Educators have a privileged position of power and trust. They respect confidentiality unless disclosure is required by law. Educators do not abuse or exploit students or minors for personal, sexual, ideological, material or other advantage. (p. 4)

The above is a statement that we can all endorse if we care for students and the other seven that are not listed here are similarly universally non-contentious. However, there is danger in an over-reliance on extrinsically based, mandated standards of accepted ethical behavior that could undermine their very purpose. In reference to the above quote our general concerns about standards are stated below along with specific questions as they relate to this particular standard.

- They can be broadly interpreted. Who can disagree with the above standard?

- They are general and may not be easily applied in diverse situations and their permutations. How can the above be applied in an individual case since it does not take the specific individuals or special circumstances into account? Teachers will still have to interpret what the specific action must be.

- They will entice some to rely on the "letter of the law" when there are more subtle issues that need to be addressed as well. With such general terms being easy to account for, how do we know if we have done the best we can for a particular student? Abuse can be very subtle. How can we account for unspoken or hidden emotional hurt?

- They suggest a dichotomy of choice, and that all actions either follow the rules or do not, when in actuality there is always a shifting grey area requiring on-going examination. It is not always clear that the best care has taken place because the standard is purposely vague to solicit consensus. How can we know that we have taken the best care or have even interpreted the standard in the most appropriate way?

- They are not enough. Rules by themselves send the message that punishment itself is preventative. There are enough jail cells being continuously occupied to suggest that punishment may not be sufficient. What are the consequences and how do we know they will be effective? Some individuals, as alluded to above, do not consider consequences in the moment of transgression.

Of course universal, non-specific standards are needed in teaching, but, as stated, they are not enough. Standards and general rules have limitations. They are separated responses from actual experience that reduce the complexity in social events in order to respond decisively. They do not consider uncertainty.

\section{Ecological Ethics}

It seems this discussion begs for a definition of ethics, and in a similar vein, a definition of morals. In general, we understand both to be some recognition of "good", of behaviors that benefit others and/or general society. If a conception of ethics is to address specific practice, it will be dependent on values which, when applied to specific situations, 
become a matter of divergent personal perspectives. We despair of a universally accepted definition of ethics, and more so, of a consensus on the values that might inform ethics. Therefore we choose a perspective that we believe provides a persuasive framework to support our thinking around this subject matter:

The core of the problem of standards may be their masking of teaching and teacher education as evaluative moral activities that shape individuals in particular ways. There is little agreement on what should be the direction of that shaping and the potential ethical and political debate that surrounds decisions about educational practice is tremendous. Why then try to still the debate? Why not engage standards dialogically as opportunities for further reconsideration and conversation. (Phelan et al., 2007, p. 245)?

In caring relationships, we try to attend to everything - moods, needs, wants, and dangers. We do this because we have a sense that all of these things are important to the well being of those cared for. It is, of course, an impossible task; it may be that small things are very important. This can heighten our sense of care, responsibility, thoughtfulness, and thoroughness. Since everything is connected, it means that we know what we do with one person will affect everyone else in the group. A simultaneous attention to both individuals and the whole group, as well as the environment that contains them, can be fostered as we think in terms of ecology.

David J. Flinders (1992) traces various conceptions of ethical thought. For the purpose of this discussion, a comparison of utilitarian and ecological ethics provides a useful contrast. Utilitarian ethics is the most familiar kind of ethics. For instance, it is commonly the type used in university ethical review committees. This type of ethical thought is based on utility. "An action or decision is considered moral if it produces the greatest good for the greatest number" (p. 102). In contrast, ecological ethics is a conception of the world, environments, or communities (including classrooms) as unified systems. "A chief characteristic of all ecological systems is that no part is capable of exercising unilateral control over the entire system" (p. 109). Members of such a system are concerned with language, relationships, and ideas in a holistic regard for their culture. Each member, whether teacher or student, is an integral part of a coevolving whole. As such, it is not enough to make discrete judgments of the ethics of specific actions or decisions. Rather, there is an ongoing process of negotiating power structures to maximize the inclusion and optimal care of all.

... as a primary teacher, I realized that everyday we take ethical risks with children. We make a constant renewal of our professional and moral promise to do our best in regard to the children and our colleagues. (Collins, 2004)

In addition to using rules and standards to give us information and perspective, teachers are also constantly monitoring each relationship and interaction. We internalize our ethics, constantly check the perspectives of those we care for, and reframe our own.

Conceiving a caring relationship as from a complex perspective, we as teachers are each a member of the system, intrinsically connected, affected by it, and we can participate with passion to influence the system - but we cannot control it. 
In terms of collective action, the understandings and interpretations that are generated cannot be completely pre-stated, but must be allowed to unfold. Control of outcomes, that is, must be decentralized. They must to some extent emerge and be sustained through shared projects, not through prescribed learning objectives, linear action plans or rigid management strategies. (Davis \& Sumara, 2005, p. 459)

Relationships respond to conversations (not just verbal ones (Collins \& Ting, 2010)), which are unplanned exchanges of ideas. Interaction patterns grow in unexpected ways.

In such interactions, one's structure is necessarily affected, although not always visibly, and he or she thus emerges a "different person." The other person involved in the interaction is similarly affected, and so the two "co-emerge". (Davis, 1996, p.10)

In complex systems, the interactions among elements create something new. In the example of a conversation, the interaction of conversational elements (words and ideas) produces other concepts, plans, attitudes, and perspectives. The interactions between teacher and student determine the quality of that relationship. Interactions are not just verbal conversations, however. There are many ways that we interact. Some are subtle and some are tacit. With children, interactions are much more than just talking.

Interactivity is, therefore, to be encouraged, maximized, and tailored to individual styles and needs. In this way, we can support each individual in the way they need and design learning opportunities accordingly. Appropriate ways of interacting must be encouraged. This is necessarily an on-going dynamic process where children constantly develop effective and respectful skills and practices for communication. These interactions often go beyond the verbal. Physical movement, gestures, even bumps, prods, and pokes often support the communicative intent of students, especially considering that many have limited verbal skills. (Collins \& Clarke, 2008, p. 1008)

A caring attitude will promote a particular kind of relationship. In turn, with continued interaction, the relationship will determine the particular kind of care that is needed. This kind of feedback loop is how ecological ethics informs us. Our ethical stance arises through our interactions rather than simply predetermined by outside standards of care.

Teachers do, and should do, whatever we can and then allow the situation to unfold without blaming our students or ourselves. A relationship is always in disequilibrium, always unfolding. We can care unconditionally, and since we are all connected within a relational system, it includes care of ourselves. We recognize that we are "good enough".

\section{Vulnerability: The Problem with Care}

In our schools, we note the increasing value of extrinsic measures of "best". These are manifest variously by grades, honor rolls, and ubiquitous awards for all kinds of performance. We notice in our own practice that perfectionism among students is becoming a debilitating problem in a growing number of cases.

Much of this may be based on the often quoted but misinterpreted Darwinian phrase "the survival of the fittest". It turns out that in both biology and society, what is best is not very clear. In social cases, it is more a matter of opinion. Biologists and 
complexivists now contend that being the fittest is not the most salient factor in adaptation and survival.

Back in Darwin's day, a contemporary of his invented a "sound bite" for natural selection: he called it "survival of the fittest", with "fit" being best adapted - not necessarily the biggest and strongest. Correctly understood, though, natural selection is survival of the fit enough. (Scott, 2005, p. 37)

Diversity is a key to growth and the continuation of species and social systems. It is not about the survival of the fittest. Rather, it is the non-survival of the non-fit or the "survival of the fit enough". There can be many ways of being fit. Diversity, rather than best, provides creativity and multiple paths of action.

In most real life situations, the best ethical practice is not always predictable. Perhaps thinking things through and individualizing ethical responses is a useful habit to acquire.

Applying this idea to individual cognition and to collective knowledge suggests that learning is not a matter of being ideally suited to external conditions, but of behaving satisfactorily. It is a not a process of selecting "correct actions" but of discarding those actions that do not work. (Davis, Sumara, \& Kieren, 1996, p. 165)

This suggests that caring teachers allow, for their own good, individual approaches for embracing their imperfections. They can learn to be "good enough" in each situation rather than some undefinable universal best.

And the last, which I think is probably the most important, is to believe that we're enough. Because when we work from a place I believe that says, "I'm enough," then we stop screaming and start listening, we're kinder and gentler to the people around us, and we're kinder and gentler to ourselves. (Brown, 2010)

The basis of relational care lies in the connection between teacher and student. We are reminded again of Capra's "collective mind". Without connection, the relationship would be one of acquaintance as opposed to a bond, of interacting in a superficial way, as opposed to a deep, personal manner. Care, as complex as it may be, comes naturally to most, but it's not that easy. While such connection is beneficial and necessary, it creates a conundrum for teachers. What makes this bond useful is the personal relationship, but by definition, the relationship permeates into teachers' personal lives.

This permeation can open teachers up to potential discomfort. For many, setting fluid "boundaries" without becoming cynical or distant is a dilemma. Often the students who require more teacher attention are those who also need the teacher to fulfill a greater number and variety of roles. As teachers attempt to do this (demonstrate care), they create a stronger relationship with the student, creating more potential for discomfort for themselves.

One of the causes of disconnection between teacher and student can be feelings of vulnerability. According to Brown (2010) a mechanism for coping with vulnerability may be to disconnect from emotional commitment. They withdraw from discomfort and (the potential for) pain, they build protection, and/or numb the emotions that arise from these connections. It seems an unfortunate path since so many of the complexivists cited 
in this discussion so far (Collins \& Clarke, 2008; Capra, 1982; Davis, 1996; Davis, Kieren, \& Sumara, 1996; Donald, 2001; Goleman, 2006) speak about the significance of interconnectedness, interactivity, and emergence that is salient in the survival of complex, adaptive systems such as individual and collective human beings.

A repeated point in this discussion is that since human relations are complex there is no formula as to how to handle any specific situation. There can be a mutual coevolution of a response to the issue. Rather than withdrawal and separation, it may be that the conversation could continue.

Hence our efforts to understand the world are perhaps better thought of in terms of interpreting our own perceptions and patterns of acting within a dynamic context than in terms of coming to know that context as somehow independent of our participation.

(Davis, 1996, p. 14)

\section{Conclusion}

The preceding discussion has been an affirmation of Noddings' challenge to care in schools. It extends her idea of connectedness among people and how that complexity defies simple procedures and solutions. Stated explicitly, the simple notion of connections, when applied to human networks, invites complexity. By embracing complexity we have extended and elucidated Noddings' notions of care when considered in real life, "organic" situations.

The challenge of caring within the complexity of real social situations is demanding and can be overwhelming. Standards and codes of ethics can be helpful, but teaching is interwoven with relationships. Relationships are dynamic and in a constant state of renewal. For a teacher to care enough and appropriately is a constant negotiation without the predictability that is seemingly assumed in the case of rules and guidelines.

To be caring and to model care is basic to being human and provides a foundation for a strong cohesive society. In order to survive the complexities of care, beyond what is publicly mandated, teachers can allow themselves to be imperfect. We can forgive ourselves when we do our best and there is still not an immediate resolution.

We contend that successes in relationships are emergent and unpredicted. They are adaptive for the growth of a particular relationship. Caring in teaching is not like curing in medicine that brings a happy resolution. Care in teaching sustains the growth of a complex ongoing relationship regardless of outcomes. Neither is care a transaction. Teachers do not necessarily receive care in return. For good teachers, care does not fit into the concept of balance between giving and taking, as is expected in business interactions.

The response of the cared-for is an act of reciprocity, but it is not the contractual reciprocity so familiar to us in traditional Western philosophy. The cared for usually cannot do for the carer what the carer can do for the cared-for, nor must he promise payment of some kind. The act of recognition is itself a form of reciprocity - completing the relation and providing confirmatory evidence that the carer is on the right track. (Noddings, 2010, p. 392) 
In teaching, we challenge the limitations of the idea of balance. Rather than simple rules and anticipated resolutions, we embrace disequilibrium as part of growth and learning.

When we discuss teaching and teacher-learner relationships in depth, we will see that teachers not only have to create caring relations in which they are the carers, but that they also have a responsibility to help their students to develop the capacity to care. (Noddings, 2005, p. 18)

Care may not be paid back but perhaps for the students of caring teachers, it may be paid forward.

\section{References}

British Columbia Ministry of Education (2012). Standards for the Education, Competence \& Professional Conduct of Educators in British Columbia, www.bcteacherregulation.ca.

Brown, B. C. (2010). Brene Brown on Vulnerability, TED Talks. http://www.ted.com/talks/lang/eng/brene_brown_on_vulnerability.html.

Brown, B.C. (2010 ). The Gifts of Imperfection: Let Go of Who You Think You're Supposed to Be and Embrace Who You Are. Center City, MN: Hazelden.

Capra, F. (1982). The Turning Point: Science, Society, and the Rising Culture. New York: Simon and Schuster.

Clarke, A. \& Collins, S. (2007). Complexity Science and Student Teacher Supervision. Teaching and Teacher Education, 23, p. $160-172$.

Collins, S. (2004). Framing the Complexity of a Participatory Democracy in a Public Primary Classroom. Journal of Research for Educational Leaders, 2 (2).

Collins, S. \& Clarke, A. (2008). Activity Frames and Complexity Thinking: Honoring Both Public and Personal Agendas in an Emergent Curriculum. Teaching and Teacher Education, 24 (4), p. 1003-1014.

Collins, S. \& Ting, H. (2010). Actors and Act-ers: Enhancing Inclusion and Diversity in Teaching and Teacher Education Through the Validation of Quiet Teaching. Teaching and Teacher Education, 26, P. 900-905.

Darling, L. F., Clarke, A., \& Erickson, G. (2007). Collective Improvisation in a Teacher Education Community. Dordrecht: Springer.

Davis, B. (1996). Teaching Mathematics: Toward a Sound Alternative. New York: Garland Publishing, Inc.

Davis, B., Sumara D. \& Kieren, T. (1996). Cognition, Co-emergence, Curriculum, Journal of Curriculum Studies. 28 (2), 151-69.

Davis, B., \& Sumara, D. (2001). Learning communities: understanding the workplace as a complex system. New Directions for Adults and Continuing Education, 92(2), 85-95.

Davis, B., \& Sumara, D. (2004). Understanding Learning Systems, Teacher Education and Complexity Science. (Proceedings of Meeting of the Western Canadian Association for Student Teaching, Alberta, Edmonton).

Davis, B. \& Sumara, D. (2005). Complexity Science and Educational Action Research: Toward a Pragmatics of Transformation. Educational Action Research, 13(3), 453-66.

Davis, B. \& Sumara, D. (2006). Challenging images of knowing: complexity science and educational research. International Journal of Qualitative Studies in Education, 18(3), 305-321.

Davis, B. \& Sumara, D. (2006). Complexity and Education: Inquiries into Learning, Teaching, and Research. New York: Routledge.

Donald, M. (2001). A Mind So Rare: The Evolution of Human Consciousness. New York: Norton \& Company.

Flinders, David J. (1992). In Search of Ethical Guidance: Constructing a Basis for Dialogue. International Iournal of Oualitative Studies in Education, 5(2), 101-15. 
Fullan, M. (2001). Leading in a Culture of Change. San Francisco: Jossey-Bass,.

Goleman, Daniel. (2006). Social Intelligence: The New Science of Human Relationships. New York: Bantam Books,.

Mercado, C.I. (1993). Caring as empowerment: School collaboration and community agency. Urban Review, 25(1), 79-104.

Mgombelo, J. (2006). Teaching and Ethics in Complexity Science: The Ethics of Absolute Unitary Being. Complicity: An International Journal of Complexity and Education, 3(1), 21 - 38. www.complicityandeducation.ca.

Murphy, P.K., Delli, L.A.M., \& Edwards, M.N. (2004). The Good Teacher and Good Teaching: Comparing Beliefs of Second-Grade Students, Preservice Teachers, and Inservice Teachers. The Journal of Experimental Education, 72(4), 69-92.

Noddings, N. (2005). Moral Education and Caring, Theory and Research in Education 8(2).

Noddings, N. (2010). Moral Education in an Age of Globalization. Educational Philosophy and Theory, $42(4), 390-96$.

Noddings, N. (2005). The Challenge to Care in Schools: An Alternative Approach to Education. New York: Teachers College Press.

Owens, L. \& Ennis, C. (2005). The Ethic of Care in Teaching: An Overview of Supportive Literature. Quest, 57(4), 392-425.

Palmer, P. J. (1999). The Grace of Great Things: Reclaiming the Sacred in Knowing, Teaching, and Learning. In The Heart of Knowing: Spirituality in Education, edited by Stephen Glazer. New York: Putnam.

Phelan, A., Erickson, G., Darling, L., Collins, S., \& Kind, S. (2007). "The Filter of Laws": Teacher Education and the British Columbia College of Teachers' Teaching Standards. Collective Improvisation in a Teacher Education Community, Springer: The Netherlands.

Piaget, J. (1977) The Development of Thought: Equilibrium of Cognitive Structures (New York, NY: Viking Press.

Polk, J. (2006). Traits of Effective Teachers. Arts Education Policy Review, 107(4), $23-29$.

Prigogine, I. (1977). Self-organization in non-equilibrium systems: From dissipative structures to order through fluctuations. Wiley: New York.

Scott, E. C. (2005). Evolution vs. Creationism: An Introduction. Berkeley: University of California Press.

Tarlow, B. (1996). Caring: A negotiated process that varies. In S. Gordon, P. Benner, \& N. Noddings (Eds.), Caregiving: Readings in knowledge, practice, ethics, and politics. 56-82. Philadelphia: University of Pennsylvania.

Tomlinson, C. A. (2003). Fulfilling the Promise of the Differentiated Classroom: Strategies and Tools for Responsive Teaching. Alexandria, VA: Association for Supervision and Curriculum Development.

Weaver, W. (1948). Science and complexity. American Scientist, 36, 536.

\section{Acknowledgements}

We wish to express our deepest thanks to Dr. Nel Noddings for her generous support and advice.

\section{About the Authors}

Steve Collins is an Instructor at the University of British Columbia in the Faculty of Education, Department of Curriculum and Pedagogy. He received a Doctorate in Curriculum Studies in 2002. He specializes in the fields of Complexity Thinking and Democratic Classrooms. His 21 years of teaching at the university have overlapped with 29 years teaching in public elementary schools. 
Hermia Ting is a Teacher in the Richmond, British Columbia public school system and has been teaching for six years. She received her Master of Educational Technology in 2011. She has an interest in Educational Reform in both teacher education and public schooling. She has co-instructed university teacher education courses, presented workshops to Teacher Education Students, and assisted with their practica.

(C) Copyright 2014. The authors, STEVE COLLINS and HERMIA TING, assign to the University of Alberta and other educational and non-profit institutions a non-exclusive license to use this document for personal use and in courses of instruction provided that the article is used in full and this copyright statement is reproduced. The authors also grant a non-exclusive license to the University of Alberta to publish this document in full on the World Wide Web, and for the document to be published on mirrors on the World Wido Woh Anu nthor usaoo is nrohihitod znithnut the ornose nermicsion of the authors 